\title{
Seelsorge für Leute ohne Seele?
}

\section{Christina Aus der Au}

Prof. Dr. theol., Mitglied der Redaktion Ethik

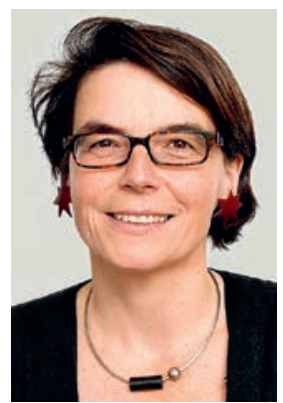

In müssigen Viertelstunden stöbere ich gerne auf Facebook herum, schmunzle über witzige Zitate und like da und dort etwas Interessantes. Und ich finde auch öfter interessante Hinweise und Gedankenanstösse. So lese ich zum Beispiel kürzlich auf der Seite eines Vertreters der Freidenker die Bemerkung: «sehr guter Vortrag am Nachmittag zu «Seelsorge für Leute ohne Seele»».

Den Vortrag hätte ich ja gerne auch gehört. Was sind Leute ohne Seele? Seelenlose? Zombies? Oder einfach voll und ganz Diesseitige? Und worin besteht dann eine entsprechende Seelsorge? Wofür wird da gesorgt? Fürs Gehirn? Für den Leib? Für das Leben hier und jetzt? Unterscheidet sich das so grundlegend von einer Seelsorge für Leute mit einer Seele?

Und überhaupt - ist es nicht etwas verkürzt, die Seele so an einen religiösen Glauben zu binden? Und das heisst doch wohl, diese mit dem Leben nach dem Tod zu identifizieren. Das meine ich durchaus selbstkritisch - meine eigene (Kirchen- und Theologen-)Zunft hat in ihrer Geschichte viel Gewicht auf das ewige Seelenheil, das Höllenfeuer und das Paradies gelegt. Und so können Atheisten und Freidenkerinnen tatsächlich auf die Idee kommen, Menschen, die nicht an Gott und das Leben nach dem Tod glauben, bräuchten keine Seele - auch wenn ich mir natürlich denken kann, dass dieser Vortragstitel vor allem provokativ sein will.

Aber der Titel hat sein Ziel erreicht - er hat mich ins Nachdenken gebracht. Was ist denn die Seele? Der vom Himmel gefallene, unsterbliche Kern des Menschen, wie es der griechische Philosoph Platon lehrte? Oder einfach das Organisationsprinzip des Körpers, wie es sein säkular anschlussfähigerer Schüler Aristoteles vertrat? Diese zwei Linien haben wir auch in der christlichen Tradition. Während sich das Alte Testament unter Seele die von Gott eingehauchte, aber ganz und gar leibliche Lebendigkeit von Menschen und Tieren vorstellt, hat sich das Christentum oft genug im Gefolge von Platon an René Descartes gehängt: Die Seele ist das ganz und gar geistige und unsterbliche Gegenstück zum Körper.

Seele kann man also so oder anders denken, mit oder ohne Körper, mit oder ohne Himmel. Aber ganz weg geht sie nicht, dafür ist sie nur schon in der Sprache zu präsent. Ich fühle mich mutterseelenallein, komme ganz beseelt aus einem Konzert, bin mit Leib und Seele bei etwas dabei, eine Freundin ist eine Seele von Mensch oder etwas ist Balsam für meine Seele. Ein seelenloser Ort wie ein seelenloser Mensch ist etwas Unheimliches. Und auch wenn die Mediziner und Medizinerinnen den Sitz der Seele bisher weder im Gehirn noch im Herzen gefunden haben, so haben sie sich doch jedenfalls mit der Psyche anfreunden müssen. In Zürich ist die «Klinik für Konsiliarpsychiatrie und Psychosomatik» bei der Psychiatrie angesiedelt, während in Basel die Psychosomatik eine Spezialabteilung der inneren Medizin ist. Und wahrscheinlich gibt es auch unter Freidenkerinnen und Freidenkern Menschen, die an Stress, Neurodermitis oder Angststörungen leiden. Dann kommen sie an der Psyche nicht vorbei. Ist es dann Seelsorge, was sie von der Psychosomatik brauchen? Oder wäre es eher Psychosorge? Dabei fällt mir auf - ist es Zufall, dass die Jugendsprache das Schimpfwort "du Psycho» kennt, aber nichts Vergleichbares mit «Seele»? Vielleicht ist Psycho hier doch nicht ganz genau das Äquivalent zur Seele.

Interessant ist auch, dass an den universitären Zentren sowohl in Zürich als auch in Basel von psychischer Verursachung gesprochen wird. Um körperliche Beschwerden verursachen zu können, muss da nicht die Psyche doch noch etwas anderes sein als der Körper? Wandeln also unsere Psychosomatiker und -somatikerinnen hier noch heimlich auf den Spuren von Platon und Descartes, obwohl sie doch dem Dualismus schon längst abgeschworen haben? Ebenso wie die Freidenker, die erst trennen - hier Körper, da Seele -, um dann die eine Seite über Bord werfen zu können.

Vielleicht hilft es, hier Aristoteles - und das Alte Testament - ernst zu nehmen. Seele als die gesamtleibliche Lebendigkeit des Organismus. Ob dieser jetzt unsterblich ist oder vermodert, ist selbst in der jüdisch-christlichen Tradition umstritten. Aber es gibt auch für gläubige Menschen - und erst recht für Menschen ohne einen Glauben an eine Transzendenz - ein Leben vor dem Tod. Und dieser Lebendigkeit, dieser Seele gilt es hier und jetzt Sorge zu tragen. Ob das jetzt verantwortungsbewusste Seelsorger sind, die in einer bestimmten religiösen Tradition verwurzelt sind, reflektierte freie Rednerinnen und Berater oder auch Ärztinnen, die sich Zeit nehmen für ihre Patienten - das alles sind Seelsorger für lebendige Leute mit einer Seele. 